splint, such as I have illustrated (Fig. $3 a$ ). It allows of easy access to the wound, and can without difficulty be modified to suit a special case. Fortunately, in gunshot wounds, the spiral fracture is rare, and, generally spealing, one bone remains unbroken. The treatment, therefore, of fiactures of the leg does not present so much difficulty as that of the thigh. For transport, however, aud for general comfort, the splint should immobilize the knee (Fig. 3 b).

\section{Fractures of the Upper Limb.}

$$
\text { Arm. }
$$

Fractures through the shoulder-joint and through the surgical neck of the humerus require no splints. 'The elbow shonld be slung at right angles and fixed by a broad bandage to the side. The dressings would probably replace the usual pad in the axilla, which should never be bulky. Shoulder shields are unnecessary and cumbrous. The patient, where practicable, should be treated in the upright position, and should have his head and shoulders well propped at night.

Where ankylosis is to be expected after a bad smash and suppuration of the shoulder, and opportunity is affordect for continuous treatment, the arm should be kept abducted slightly forward, and slightly rotated inwards (Fig. 4). This assures a much extended range of movement at a more useful radius, such range of movement being brought about by the action of the scapula. This position need not be adopted if the patient has to be transported, as it can be established after the arrival home. Fractures through the elbow or immediately above the condyles are best treated without splints. If possible, the arm should be kept flexed well above a right angle. Suppurating cases in the adult will not admit of the very acute flexion which we insist upon in the case of children. If, for a rare reason, a splint has to be applied, the internal wooden angular splint must be avoided, because it is always chumsy and often causes deformity, and a splint as illustrated (Fig. $5 a$ and $b$ ) uscd.

Fractures of the middle and lower middle portions of the shaft of the humerus, where dressings have to be frequently changed, require very gentle handling, and I illustrate two splints which may be found very useful. One is a modified Thomas knee splint used to maintain extension in the abducted position, the patient being recum. bent (Fig. $6 a$ and $b$ ). The other is a modified Thomas linmerus extension splint (Fig. $7 a, b$, and $c$ ), to be used when the patient can walk about or sit up in bed. Either splint permits of easy dressing, and maintains adequate fixation. $A s$ so much destruction of bone may be produced by modern shrapnel, and even by rifle bullet, great care must b. taken to prevent over-extension, otherwise non-union will ensue.

\section{Forearm.}

The chief disability to be feared in fractures of the shafts of the bones of the forearm is inability to supinate the forearm completely. The trouble usually arises where both bones are broken, but it may occur where the radius alone is involved. We must remember that the whole length of the posterior border of the ulna is subcutaneous and is practically straight. On this straight ulna the curved radius rotates like the handle of a bucket. We must therefore attend to two points. First, we must keep the ulna straight; second, we must not interfere with the natural curve of the radins. That is to say, there must be no lateral pressure of bandage cr. splint on the middle of the shaft of the radius. In dealing, ther'efore, with these fractures, whether one or both bones be broken, the position of supination should invariably be maintained (Fig. 8). This is even more important in septic compound fractures than where no complication exists. Neglect of this important point will often result in a locking of the bones in pronation. We must remember that in nearly all neglected fractures of the forearm, supination and not pronation is defective.

Wrist and Hand.

I have seen several cases of gunshot wounds through the wrist, and they have been mostly treated with the hand in line with the forearm-that is, midway between palmar and dorsiflexion. This is fatal to a useful joint. In order that the fingers may maintain their grasping power, all injuries of the wrist-joint should be treated in the dorsiflexed position, as shown in the illustration (Fig. $9 a, b$, and c). Fractures of the hand may be immobilized as shown (Fig. $10 a, b$, and $c$ ).

Retention of Loose Pieces of Bone.

I do not intend to deal with the surgical considerations involved in the treatment of the suppurating wound. Many distinguished surgeons are devoting themselves to this problem. It may be well, however, to offer a word of warning against the destruction of loose pieces of bono removed from the wound. If quite loose they can be taken out, cleaned, and replaced. Even in the presence of pus they may unite. Suppurative compound fractures unite well if time be given them; a common source of failure is due to the removal of bone.

Preparation of Splints.

The appliances which I have described can be obtained from F. H. Critchley, 21, Great George Square, Liverpool and for the convenience of surgeous at the front I append the measurements required when a splint is ordered.

Abduction Frame (Fig. $1 a$ and $d$ ).-Give measurements from nipple to exterval malleolus, and state left or right. For an nipple to exterval malleolus, and state left or right. Fo

Bed Knee Splint (Fis. 2 a).-From fork to heel, also circum. ference of thigh at fork.

Long Foot Splint (Fig. 3 a).--Length of foot, also heel to knee.

Short Hand Splint (Fig. 9 a).-From palmar flexure of wrist to below metacarpo-phalangeal range, usually $2 \frac{1}{2}$ in.

Long Hand Splint (Fig. 10 a).--Same as short, but to finger ends.

Extension Splint for Arm (Fig. 6 a).-Circumference of arm at junction of shoulder and from axilla to finger-tips.

Angular Elbow Splint (Fig. 5 a).-Wrist to olecranon, and olecranon to tip of shoulder.

Humcrus Extension Splint (Fig. 7 a).-Wrist to olecranon, olecranon to axilla, and circumference of arm round shoulder.

Frequently the unaffected limb can be measureal to ensure correct length, etc.

\section{THE BACTERICIDAL ACTION OF COLLOSOLS OF SILVER AND MERCURY.;}

BY

\author{
Professor C. P. MARShaLL, M.D., \\ AND \\ G. B. KILLOH, M.B. \\ MEDICAI. SCHOOL, DUNDEE.
}

Is March of 1911 Crookes introduced two new preparations-collosol argentum and collosol hydrargyrum-containing 1 in 2,000 of silver and of mercury respectively in a colloidal form. From his bacteriological experiments with these preparations he concludes: "I know of no microbe that is not killed in laboratory experiments in six minutes." These experiments consisted in adding the collosol to nutrient broth infected with a micro-organism and making streak cultures from the mixture on agar plates at definite intervals of time. This method and the slight modification of it adopted in the case of gonococcus experiments appeared to us to show little more than the antiseptic action of these prejarations, since, after subculture on a semisolid medium like agar jelly, the micro. organisms are still in an environment of the antiseptic little removed in strength from that of the original mixture.

We therefore performed the following experiment: A vigorous twenty-four hour's' growth of Bacillus coli communis on agar was swamped with collosol argentum, and after ten minutes the collosol was poured off and tho growths carefully washed with sterile distilled water to remove any collosol adhering to the micro-organisins or the medium; inoculations were then macie on agar and in MacConkey's medium and the tubes incubated for twentyfour hours at $37^{\circ} \mathrm{C}$. Growth occurred in both media.

Further experiments on the bactericidal and antiseptic actions of these preparations were made in the autumu of 1911, and are summarized in the succeeding tables. The preparations were obtained through a retail pharmacist, and when examined after dilution by the ultramicroscope showed the usual structure of inorganic colloids. There was very little clumping of the particles, and no other evidence of coagulation.

* Read at a meeting of the Section of Pharmacology at the Aqnual 


\section{Bactericidal Experiments.}

The method adopted to determine the bactericidal action was to add a loopful of micro-organismal emulsion to $5 \mathrm{c.cm}$. of the collosol or this diluted to known strengths with sterile distilled water, and after periods of five, ten, fifteen, or more minutes inoculating $5 \mathrm{c.cm}$. of MacConkey's medium or lemco broth, according to the micro-organism used, with a loopful of the mixture and incubating at $37^{\circ} \mathrm{C}$. The micro-organismal emulsion was made by adding three or four loopfuls of a twenty-four hours' growth of the various organisms on agar to 1 c.cm. of sterile distilled water. Controls were employed in all experiments, and the usual aseptic precautions were taken.

A large number of experiments were made with varions lilutions and with practically uniform results. In a few instances, with dilutions around the limit of bactericidal power, sometimes a positive, sometimes a negative result was obtained. These are indicated in the tables by a double sign. For brevity only those experiments showing the limit of bactericidal action are given. It is to be understood that half the strengths mentioned gave positive results, and double the strengths negative results, with all the times indicated; + means growth, 0 means no growth, and they refer, unless otherwise stated, to observations made after twenty-four hours' incubation. The order of the organisms is that in which they were in vestigated, and the times given are those during which the organism was submitted to the preparation or the dilution mentioned.

Collosol Hydrargyrum.

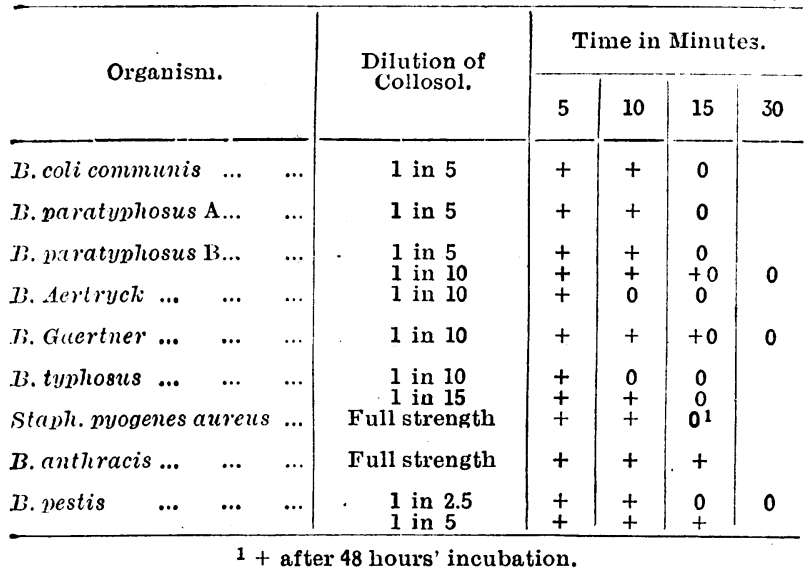

As it is not improbable that a part, if not the whole, of the bactericidal action of colloidal mercury is due to a portion undergoing ionization, a few experiments were made to determine whether the presence of such salts as are likely to increase the amount of mercury in solution has any intensifying power on the bactericidal action of this preparation. The experiments were carried out in the manner described, except that a sterile solution of 0.9 per cent. sodium chloride was used as a diluent in place of sterile distilled water. As the following experiment shows, intensification of action does occur under these conditions:

\begin{tabular}{c|c|c|c|c}
\hline \multirow{2}{*}{\begin{tabular}{c|c|c|} 
Organism. \\
33. coli communis
\end{tabular}} & $\begin{array}{c}\text { Dilution of } \\
\text { Collosol. }\end{array}$ & \multicolumn{2}{|c}{ Time in Minutes. } \\
\cline { 2 - 5 } & $\ldots$ & 5 & 10 & 15 \\
\hline & 1 in 35 & 0 & 0 & 0 \\
1 in 40 & + & 0 & 0 \\
1 in 42.5 & + & + & 0 \\
& 1 in 50 & + & + & + \\
\hline
\end{tabular}

It is possible that such an intensification may occur when the preparation is injected into the blood or applied to the tissues.

In order to obtain the influence of ionized mercury for comparison with the results obtained with collosol of mercury similar experiments were mads with mercuric chloride. The strengths of the solutions in these are given in terms of mercury, and for comparison with those of the collosol must be divided by 2,000 .

\section{Mercuric Chloride.}

\begin{tabular}{|c|c|c|c|c|c|c|}
\hline \multirow{2}{*}{\multicolumn{3}{|c|}{ Organism. }} & \multirow{2}{*}{$\begin{array}{l}\text { Strength, } \\
\text { calculated as } \\
\text { Mercury. }\end{array}$} & \multicolumn{3}{|c|}{ Time in Minutes. } \\
\hline & & & & 5 & 10 & 15 \\
\hline B. coli communis & ... & ... & 1 in 200,000 & + & 0 & 0 \\
\hline B.paratyphosus 1; . & $\ldots$ & $\ldots$ & 1 in 200,000 & + & + & 0 \\
\hline B.paratyphosus 1 . & ... & $\cdots$ & 1 in 200,000 & + & 0 & 0 \\
\hline Stuph, pyogencs aurue & & $\ldots$ & 1 in 100,000 & + & 0 & 0 \\
\hline B. typllosus & $\ldots$ & $\ldots$ & 1 in 400,000 & + & 0 & 0 \\
\hline
\end{tabular}

Similar experiments carried out with collosol of silver showed that this preparation even in full strength had no bactericidal action whatsoever. Nor had the addition of salts-for example, sodium sulphate in 1.3 per cent. strength-any influence in inducing a bactericidal effect.

The experiments with the undiluted collosol were as follows :

\begin{tabular}{|c|c|c|c|c|c|c|c|c|}
\hline \multirow{2}{*}{\multicolumn{2}{|c|}{ Organism. }} & & \multirow{2}{*}{$\begin{array}{l}\text { Strength of } \\
\text { Collosol. }\end{array}$} & \multicolumn{5}{|c|}{ Time in Minutes. } \\
\hline & & & & 5 & 10 & 15 & 30 & 60 \\
\hline B. coli communis ... & $\ldots$ & $\ldots$ & Full strength & + & + & + & & \\
\hline B. typhosus $\quad \ldots \quad \ldots$ & $\ldots$ & $\ldots$ & ." & + & + & + & & \\
\hline Staph. pyogenes aurcus & & $\ldots$ & & + & + & + & & \\
\hline B. anthracis... $\quad \ldots$ & $\ldots$ & $\therefore$ & $"$ & + & + & + & & \\
\hline B.pestis $\quad \ldots \quad \ldots$ & $\ldots$ & $\ldots$ & ,. & & & + & & + \\
\hline B. Gacrtner ... _.. & $\ldots$ & $\ldots$ & , & & & + & & + \\
\hline B. Danys: $\quad \ldots \quad \ldots$ & $\ldots$ & $\ldots$ & " & & & + & + & \\
\hline B. paratuphosus ]; & $\ldots$ & $\ldots$ & " & & & + & + & \\
\hline B. paratuphosus A & $\ldots$ & $\cdots$ & ". & & & + & + & \\
\hline
\end{tabular}

Experiments made in a similar manner with silver nitrate solutions, as representing ionized silver, gave the following results.

\begin{tabular}{|c|c|c|c|c|c|c|}
\hline \multirow{2}{*}{ Orgsanism. } & & & \multirow{2}{*}{$\begin{array}{l}\text { Strength, } \\
\text { calculated as } \\
\text { Silver. }\end{array}$} & \multicolumn{3}{|c|}{ Time in Minutes. } \\
\hline & & & & 5 & 10 & 15 \\
\hline B. coli communis & $\ldots$ & $\cdots$ & $\begin{array}{l}1 \text { in } 2,000,000 \\
1 \text { in } 2,500,000\end{array}$ & $\begin{array}{l}0 \\
+\end{array}$ & $\begin{array}{c}0 \\
+\end{array}$ & $\begin{array}{l}0 \\
+\end{array}$ \\
\hline D. paratyphos:ts I? & $\ldots$ & $\ldots$ & $\begin{array}{l}1 \text { in } 1,003,000 \\
1 \text { in } 1,500,000\end{array}$ & $\begin{array}{l}0 \\
+\end{array}$ & $\begin{array}{l}0 \\
+\end{array}$ & $\begin{array}{l}0 \\
+\end{array}$ \\
\hline B. Acrtrycl: & $\cdots$ & $\ldots$ & $\begin{array}{l}1 \text { in } 2,000,000 \\
1 \text { in } 2,500,000\end{array}$ & $\begin{array}{l}0 \\
+\end{array}$ & $\begin{array}{l}0 \\
0\end{array}$ & $\begin{array}{l}0 \\
0\end{array}$ \\
\hline \multicolumn{2}{|c|}{ staph. pyogencs aureus. } & ... & $\begin{array}{l}1 \text { in } 400,000 \\
1 \text { in } 500,000\end{array}$ & $\begin{array}{l}0 \\
+\end{array}$ & $\begin{array}{l}0 \\
0\end{array}$ & $\begin{array}{l}\mathbf{0} \\
\mathbf{0}\end{array}$ \\
\hline
\end{tabular}

Antiseptic Action.

Some experiments on the antiseptic action of the two collosols were carried out by adding known quantities of them to $5 \mathrm{c.cm}$. of nutrient medium, and afterwards inoculating with a loopful of micro-organismal emulsion and incubating. The results are summarized in the following tables:

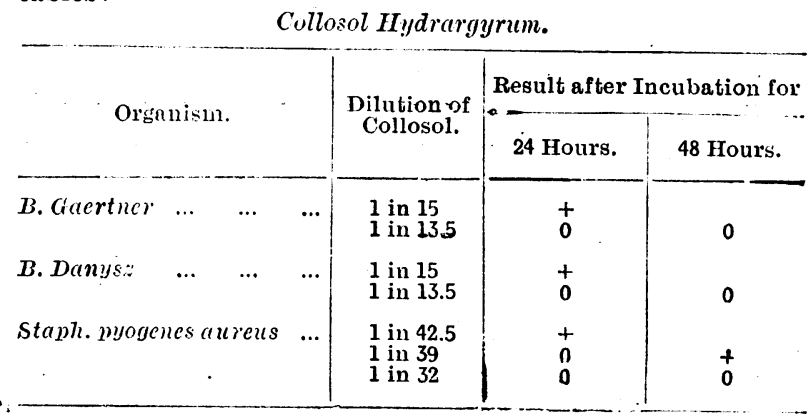


Collosol Argentum.

\begin{tabular}{|c|c|c|c|c|c|c|}
\hline & & & & & Result after & ubation for \\
\hline & & & & & 24 Hours. & 48 Hours. \\
\hline B. coli commu & $n i s$ & $\ldots$ & $\ldots$ & $\begin{array}{l}1 \text { in } 26 \\
1 \text { in } 17.5\end{array}$ & + & 0 \\
\hline B. paratyphos & sus $\Lambda$ & $\ldots$ & $\ldots$ & $\begin{array}{l}1 \text { in } 26 \\
1 \text { in } 17.5\end{array}$ & $\begin{array}{l}+ \\
0\end{array}$ & 0 \\
\hline B. paratyphos & sus $\mathrm{B}$ & $\therefore$ & $\ldots$ & $\begin{array}{l}1 \text { in } 26 \\
1 \text { in } 17.5 \\
1 \text { in } 135\end{array}$ & $\begin{array}{l}+ \\
+ \\
0 \\
0\end{array}$ & $\stackrel{+}{0}$ \\
\hline B. Aertryck & $\ldots$ & $\ldots$ & $\ldots$ & $\begin{array}{l}1 \text { in } 26 \\
1 \text { in } 17.5\end{array}$ & $\begin{array}{l}+ \\
0\end{array}$ & 0 \\
\hline B. Gaertner & $\ldots$ & $\ldots$ & $\ldots$ & $\begin{array}{l}1 \text { in } 26 \\
1 \text { in } 17.5\end{array}$ & + & 0 \\
\hline B. Danysz & $\ldots$ & $\ldots$ & $\cdot \ldots$ & $\begin{array}{l}1 \text { in } 32 \\
1 \text { in } 26 \\
1 \text { in } 135\end{array}$ & $\begin{array}{l}+ \\
0 \\
0\end{array}$ & $\stackrel{+}{0}$ \\
\hline Staph. pyogen & ies ar & ureus & $\ldots$ & $\begin{array}{l}1 \text { in } 365 \\
1 \text { in } 34\end{array}$ & $\begin{array}{l}0 \\
0\end{array}$ & $\stackrel{+}{0}$ \\
\hline
\end{tabular}

From these experiments it will be seen that both these preparations have considerable antiseptic power, and that the silver collosol is the more powerful of the two. Coursidering the absence of bactericidal action when tested under favourable conditions; the antiseptic action of this preparation is interesting. The explanation we hope to give in a later communication.

\section{COLLOSOL ARGENTUM AND ITS DPHTHALMIC USES.}

BY A. LEGGE ROE, L.R.C.P., L.R.C.S.I.,

OPHTHALMIC SURGEON, HULL ROYAL INFITMMARY AND̆ HULï AND SCULCOATES DISPENSAIIY.

Colmosol Argentum is a clear sherry-colonred-liquid, and, as described by the makers, is a solution containing the metal -silver in a colloid form. The silver is present in a metallic state, not as a salt. The actual particles are of extrome minuteness and they pass readily through the pores of a filter, and are visible only under the ultra. microscope. They show great uniformity in size, and exhibit marked brownian movements. It is claimed for this preparation that no microbe is known that is not killed in laboratory experiments in six minutes.

The opinion that I have formed as to its value may be summed up in very few words: It is the most uséful preparation that has been placed in our hands since the introduction of cocaine. I have used it many thousands of times and have never known it cause the slightest irrita tion, and it may be used for many months without staining the comjunctiva.

The first time I had occasion to use it was in a case of gonorrhoaal ophthalmia in an adult. lie had been treated for a week with 5-grain solution of silver nitrate neutralized immediately with saline solution once daily, and the eye irrigated every hour with mercury perchloride solution, 1 in 7,000 . There was very great chemosis, and a profuse purulent discharge was running down the cheek long before the time for irrigation came round again. A small central ulcer of the cornea had appeared. The same treatment was continued, and, in addition, collosol argentum drops were introduced into the eye after each irrigation. In thirty-six hours the discharge had completely stopped, there was no extension of the ulcer, and the eye made a rapid recovery, leaving only a faint nebula. I have treated three other cases in adults, with similar results. The last case, a woman, was treated by collosol only, and was discharged cured from the infirmary in five days.

In purulent ophthalmia of infants the same treatment is used, and I am certain that if this treatment was adopted in every case early, there would be no such thing as impaired vision or blindress from this cause. Many cases are treated in the out-patient department of the dispensary, and the drops being absolutely harmless may be safely trusted to the friends. The child is brought up once daily for the silver nitrate drops; the eyes are washed out every hour at home, and the collosol drops put in.
In infected ulcers of the cornea and hypopyon ulcer, of ivhich I am sorry to say we have a great experience at the infirmary, I have had better results from coliosol than from any other treatment, and tapping of the anterior chamber, the cautery and other operative procedures are now rarely required; if perforation does occur it is smaller and more manageable. 'The pupil is lept dilated with atropine, and the collosol is used every tro hours.

In the various other forms of ulcer of the cornea, especially in the early stages, in addition to keeping the pupil dilated, no better treatment can be adopted, followed by calomel dusting, and yellow oxide of mercury ointment as the ulcer begins to heal.

In interstitial Reratitis it is undoubtedly of the greatest value. I have had many cases in adults, in which from complete opacity the cornea has become absolutely clear in fiom three to fire months, and anyone who has had much experience of this disease in adults knows how often permanent impairment of sight results, and how long the treatment used to last, especially if irritants had been used before coming under treatment. The eye is liept under atropine or, preferably, scopolamine, and the collosol is dropped in three times a day, the eye being kept closed afterwards for five minutes. When all active symptoms have disappeared, and not until then, if any opacity remains, yellow oxide or mercury ointment may be used; but if treated throughout as described above I am sure this will rarely be necessary.

In the various forms of blepharitis, collosol affords the best chance of a cure. The following.case illiastrates its value in one of these conditions:

Blepharitis Ulcerosa.-A lady, aged 29, a visitor to the town, acting under the pressure of her friends, came to interview me. "I do not expect that you will be able to do me much good, as I have been under the care of an ophthalmic surgeon in $\mathrm{my}$ own town for three years, and you see what I look like now.. If you are able to do me any good I will stay here three months.' I ordered her to bathe the eyelids with a borax lotion three times a day, and then very gently to remove every particle of scab, after which she was to lie on her back, with her head thrown back, and have the collosol dropped on the closed lids; allowing it to soak for five minutes. In six weeks she went. home cured.

In dacryocystitis, after probing collosol argentum is a great help. The sac should be first syringed out with saline solution, and, after expressing any that remains, the sac should be filled with collosol with the syringe. In cases of long standing this will not be sufficient; the sac should be incised and plugged with ribbon gauze, and for about a week the sac should be dressed daily by inserting into it ribbon gauze soaked in 10 per cent. solution of potassium bichromate, or the lining membrane of the sac should be scraped. The wound is then allowed to close and the collosol injections continued.

For burns of the cornea, conjunctiva or lids, nothing will keep them in an aseptic condition better than collosol ointment, 50 per cent.

My routine treatment of wounds of the cornea, sclerotic or conjunctiva is collosol every four hours, and in my hands it has proved most successful. This is also my treatment in preparing for operation an eye from which there may be any discliarge.

In the varicus forms of conjunctivitis I have not found it to be so efficient as the ordinary remedies. I may say that collosol is always used as supplied, and not diluted. This is a record of my own experience in the use of it during the last three years.

CATERing for the sick, not always an easy matter even in favourable circumstances, becomes doubly difficult on active service, when meals suitable for patients in every stage of disease and exhaustion have to be prepared out of whatever happens to be procurable at the moment. 'This is a problem sufficient at times to tax the ingenuity of a Vatel; and the War Cookery Book for the Sicli and Wounded, recently compiled by Miss Jessie M. Laurie (Londlon: T. Werner Laurie; 6d. net) should do much to lighten the task of those entrusted with the cooking arrangements in the field hospitals of to-day. The book contains a large number of simple and nutritious dishes, with full instructions as to their preparation; and the convenience of the cook has been considered in every detail of its arrangement, the recipes being printed in large type on strons paper, which should not easily tear or become detached, even with constant usage. 